\title{
The Study of a Role of TRPC1 Protein in Formation of Molecular Structure of the Receptor- and Store-Operated Calcium Ionic Channels
}

\author{
S. V. L'vovskaja, V. A. Vigont, O. A. Zimina, A. Yu. Skopin, L. N. Glushankova, \\ E. V. Kaznacheyeva, and G. N. Mozhaeva \\ Institute of Cytology, Russian Academy of Sciences, St. Petersburg, Russia; \\ e-mail: ozimushka7@mail.ru
}

DOI: $10.1134 / \mathrm{S} 1990747809030337$

Our research was devoted to the studies of the TRPC1 protein role in formation of the ionic channels transferring calcium in response to activation of membrane receptors and to calcium store depletion. We used HEK293T cells with TRPC1 suppression.

$\mathrm{Ca}^{2+}$ influx was estimated using the intracellular calcium level measurements by fluorescent calcium-selective probes. It was shown that in these cells there is a huge decrease $(\sim 70 \%)$ in $\mathrm{Ca}^{2+}$ entry either in response to UTP application and to passive store depletion by thapsigargin application (thapsigargin is a specific inhibitor of the calcium ATPase of endoplasmic reticulum).

The whole-cell experiments have shown similar data: receptor- and store-operated $\mathrm{Ca}^{2+}$ influx in HEK293T with suppressed TRPC1 expression was significantly lower than in control cells. The obtained data suggest that TRPC1 protein suppression considerably changes calcium-transferring ways in the cells.

The work was supported by the Russian Foundation for Basic Research (project nos. 07-04-01107a and 0704-01224), the Molecular and Cellular Biology RAS program, the SS-1135.2008.4. 